\title{
The Use of Different MS Techniques to Determine Glutathione Levels in Marine Tissues
}

\author{
Adriana Mika • Edward Skorkowski • Piotr Stepnowski
}

Received: 12 April 2012 / Accepted: 30 July 2012 /Published online: 18 August 2012

(C) The Author(s) 2012. This article is published with open access at Springerlink.com

\begin{abstract}
Several techniques were used, mainly mass spectrometry connected with gas chromatography, matrixassisted laser desorption with ionization time-of-flight and mass spectrometry connected with liquid chromatography. A major problem was encountered in determining glutathione, which can be conditioned by the $\mathrm{pH}$ and selected reducing agents. The GSH form can be oxidized through derivatization, and a small glutathione amount in the biological samples may hinder the determination process. Another problem is the existence of a metal ion in the tested organism; therefore, often a reagent with a chelating function is added to the sample and the mobile phase in liquid chromatography is applied with appropriate polarity for GSH and GSSG. We determined the concentrations of total, reduced, and oxidized glutathione in the liver, hepatopancreas, muscle, and gonad tissues of brown shrimp (Crangon crangon) and fish (Psetta maxima and Clupea harengus membras). The highest concentrations of tGSH were recorded in the shrimp hepatopancreas $\left(7.21 \pm 0.011 \mu \mathrm{mol} \mathrm{g}^{-1}\right.$ wet

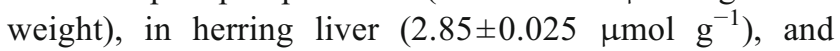
in turbot liver $\left(1.86 \pm 0.063 \mu \mathrm{mol} \mathrm{g}{ }^{-1}\right)$. In turn, the highest concentrations were reported for GSSG in the muscle of shrimp
\end{abstract}

A. Mika $(\bowtie) \cdot$ P. Stepnowski

Department of Environmental Analysis, Faculty of Chemistry, University of Gdańsk, ul. Sobieskiego 18/19, 80-952 Gdańsk, Poland e-mail: amika@chem.univ.gda.pl

A. Mika $\cdot$ E. Skorkowski

Department of Molecular Evolution, Faculty of Biology,

University of Gdańsk,

Wita Stwosza 59,

80-308 Gdańsk, Poland $\left(0.140 \pm 0.000204 \mu \mathrm{mol} \mathrm{g}^{-1}\right)$, and in the testis of turbot $(0.063 \pm$ $\left.0.000170 \mu \mathrm{mol} \mathrm{g}^{-1}\right)$ and herring $\left(0.009 \pm 0.000015 \mu \mathrm{mol} \mathrm{g}^{-1}\right)$. We also investigated seasonal changes in the concentrations of glutathione in the muscle of $C$. crangon shrimp in the annual cycle. The lowest values of total glutathione were recorded during spring and autumn, which could be correlated with the increase in lipid peroxidation and oxidative stress.

Keywords Fish · Glutathione · HPLC-MS/MS · GC-MS . MALDI-TOF/MS · Toxicology

$\begin{array}{ll}\text { Abbreviations } & \\ \alpha \text {-HCCA } & \alpha \text {-Cyano-4-hydroxycinnamic acid } \\ \text { DAD } & \text { Diode array detector } \\ \text { DHB } & \text { 2,5-Dihydroxybenzoic acid } \\ \text { DTNB } & \text { Ellman's reagent (5,5-dithio-bis- } \\ & \text { 2-nitrobenzoic acid) } \\ \text { DTT } & \text { Dithiothreitol } \\ \text { GC-MS } & \text { Gas chromatography-mass } \\ & \text { spectrometry } \\ \text { GSH } & \text { Reduced glutathione } \\ \text { GSSG } & \text { Oxidized glutathione } \\ \text { HPLC-MS/MS } & \text { High performance liquid } \\ & \text { chromatography-tandem } \\ & \text { mass spectrometry } \\ \text { MALDI-TOF/MS } & \text { Matrix-assisted laser desorption } \\ & \text { with ionization time of flight } \\ \text { MRM } & \text { Multiple reaction monitoring } \\ \text { MS } & \text { Mass spectrometry } \\ \text { NSECM } & N, S \text {-Ethoxycarbonyl } \\ \text { ROS } & \text { methyl esters } \\ \text { SIM } & \text { Reactive oxygen species } \\ \text { tGSH } & \text { Single ion monitoring } \\ \text { TFA } & \text { Total glutathione } \\ & \text { Trifluoroacetic acid }\end{array}$




\section{Introduction}

\section{Short Characteristic of Glutathione}

$\gamma$-L-Glutamyl-L-cysteinylglycine is an important intracellular tripeptide whose content changes in different tissues and achieves concentrations of between 1 and $10 \mathrm{mM}$ ( $\mathrm{Ji}$ and Leeuwenburgh 1995; Iwasaki et al. 2009). Some authors note GSH in a concentration of $12 \mathrm{mM}$, where $1 \%$ is an oxidized form of glutathione (Camera and Picardo 2002), apart from the mitochondria, where GSSG accounted for up to $25 \%$ of GSH (Camera and Picardo 2002). The content of glutathione depends on the cell structure and function, oxidative capacity, external conditions (photoradiation), and influence of other tissues (Ji and Leeuwenburgh 1995). Glutathione is the major antioxidant in cellular immunity and a detoxificant, and it keeps proper redox homeostasis necessary for the organism's correct functioning (Circu and Aw 2008). GSH is the most important reservoir of non-protein thiols in the organism (Ji and Leeuwenburgh 1995). GSH is connected with xenobiotics, such as free radicals or hydrogen peroxides, which are responsible for oxidative stress, and they are excreted as mercapturic acids and derivatives of glutathione. Glutathione conjugates are connected with steroids, prostaglandins, and leukotrienes (Iwasaki et al. 2009). The highest concentration of glutathione is described in the eye retina $(10 \mathrm{mM})$ and the lowest in blood plasma $(0.05 \mathrm{mM})$ (Lomaestro and Malone 1995; Ji and Leeuwenburgh 1995). In crustaceans, the synthesis of GSH occurs in the hepatopancreas and the gills, and synthesis of GSH is better with higher luminous intensity (Maciel et al. 2004). With the growing number of redox reactions, the metabolism and production of reactive oxygen species (ROS) decrease glutathione levels (Fanjul-Moles et al. 2009). The second reason is a steadily decreasing amount of polyunsaturated fatty acids. According to Fanjul-Moles et al. (2009), the Procambarus clarkii membrane is very rich in phospholipids and PUFAs, and even low exposition to light as well as the lowest possibility of production of ROS induce a decrease in important components of the membrane and open up access into the organism (Balzer et al. 1997).

\section{Short Review of a Few Techniques \\ Often Used to Determine Glutathione}

Glutathione was detected by spectrophotometry, fluorometry, and the EC or HPLC methods (Pastore et al. 2003; Bouligand et al. 2006). Information on determining glutathione is first dated to 1958 (Ellman 1959). This was the spectrophotometric method with Ellman's reagent (5,5-dithio-bis-2-nitrobenzoic acid). According to Guan et al. (2003), the addition of Ellman's reagent increases the analyte chemical stability and accuracy of the test, and protects the protein thiols (Guan et al. 2003). In the fluorometric methods, the authors applied $o$-phthaldialdehyde
(OPA) as the fluorescent reagent to a reaction with amino acids which was used to determine GSH and GSSG (Cohn and Lyle 1966; Hissin and Hilf 1976). The next method was capillary electrophoresis (EC), which was first used by Piccoli et al. (1994), and high performance liquid chromatography (HPLC) with various detection techniques-ECD, UV, FL (fluorescence detector) with $N$-ethylmaleimide and Sander's reagent (2,4-dinitrofluorobenzene) derivatives in HPLC-UV (Camera and Picardo 2002; Guan et al. 2003; Pastore et al. 2003; Bouligand et al. 2006; Iwasaki et al. 2009; Monostori et al. 2009), and 2-(4- $N$-maleimidophenyl)-6-methoxybenzofuran (NPM) in HPLC-FL (Camera and Picardo 2002). The next method to be used was NMR, precisely ${ }^{1} \mathrm{H}$ MRS, as described by Trabesinger et al. (1999) and Trabesinger and Boesiger (2001), who recorded a few limitations to the application of this method, a lack of distinction between reduced and oxidized glutathione, problems with its application in a clinical laboratory, it not being fully accessible, and complicated conditions for measurements (Pastore et al. 2003). It is impossible not to mention the technique of GC-MS and LC-MS - connection chromatography and mass spectrometry are excellent techniques for determining low molecular mass components. In the GC-MS technique, GSH was performed in $N, S$-ethoxycarbonyl methyl ester derivatives. This is a very sensitive method; however, it is time consuming and expensive because of the many specific reagents (Humbert et al. 2001; Capitan et al. 1999; Küster et al. 2008). What is more, many variables may disrupt the analysis process, such as an incorrect $\mathrm{pH}$ (Camera and Picardo 2002; Monostori et al. 2009) or the temperature of GC-MS measurement (Iwasaki et al. 2009). A correct $\mathrm{pH}$ between 2.5 and 3.5 should be formed in the application of HPLC with various detectors. This depends on the kind of mobile phase (Yilmaz et al. 2009). A high pH favors the formation of glutathione conjugated with various compounds (Kato et al. 2003) or the oxidation of GSH (Pastore et al. 2003). Therefore, it is recommended that various acids be added such as $N$-ethylmaleimide (NEM), iodoacetic acid (IAA), 2-vinyl pyridine (Pastore et al. 2003), trichloroacetic acid (Pastore et al. 2003), or trifluoroacetic acid (TFA) (Mitamura et al. 2007). In turn, a low $\mathrm{pH}$ (about 1) causes a decrease in the intensity of the peak (Frassanitoa et al. 1998).

HPLC-MS/MS plays a significant role in clinical chemistry and laboratory analysis (Pastore et al. 2003; Iwasaki et al. 2009; Yilmaz et al. 2009) and is the most effective instrument in biological research studies (Guan et al. 2003; Iwasaki et al. 2009). A universal source of ionization is electrospray with a triple quadrupole mass spectrometer (Camera and Picardo 2002). Using the mass spectrometer as the detector increases selectivity of the analytical method (Guan et al. 2003). This method is characterized by high sensitivity, high-throughput potential, specificity, and detection of very low molecular components (Loughlin et al. 2001; Guan et al. 2003; Pastore et al. 2003; Bouligand et al. 2006). The other characteristics of 
why it is so popular is its rapid analysis, sensitivity (Guan et al. 2003), and the fact that LC-MS does not require the derivatization process (Pastore et al. 2003). In choosing the method for determining glutathione, the following are important: sample collection, the separation technique used, selected detection, the sample matrix content, and the composition and storage of samples (Camera and Picardo 2002).

In conclusion, mass spectrometry (MS) is a suitable technique for the analysis of low molecular mass thiols (Pastore et al. 2003). These factors were the reason for determining glutathione in marine tissues by MS techniques.

\section{Material, Method, and Analytical Techniques Used}

\section{Biological Material}

Crangon crangon muscles used to determine glutathione levels were collected from the coastal area of the Gulf of Gdansk near Sobieszewo Island between July 2010 and November 2011. C. crangon were decapitated and the muscles and hepatopancreases were dissected and frozen at $-80{ }^{\circ} \mathrm{C}$ in glass tubes. After creating a simple technique to determine the GSH, this technique was used to identify the content of total glutathione as well as reduced and oxidized glutathione in other marine organisms living in similar environmental conditions. To determine variability of the results, they were compared with Student's $t$ test and were significant at $p<0.05$. The data are expressed as means \pm standard error (SE).

\section{Chemicals}

\section{Chemicals for $G C-M S$}

Dithiothreitol (DTT), trichloroacetic acid (TCA), phosphate buffered saline (PBS), ethyl chloroformate, ethyl acetate, methanol, sodium chloride, and hydrochloric acid were obtained from Sigma-Aldrich (Poznań, Poland). The GSH and GSSG standards were supplied by Sigma-Aldrich.

\section{Chemicals for MALDI-TOF/MS}

2,5-Dihydroxybenzoic acid (DHB), $\alpha$-cyano-4-hydroxycinnamic acid ( $\alpha$-HCCA), methanol, acetonitrile, $1 \mathrm{mM}$ ammonium acetate, $0.1 \%$ TFA, and $50 \%$ sulfosalicylic acid (SSA) were obtained from Sigma-Aldrich. The GSH and GSSG standards were supplied by Sigma-Aldrich.

\section{Chemicals for HPLC-MS/MS}

5,5'-Dithiobis-2-nitrobenzoic acid (DTNB), methanol, acetonitrile, $1 \mathrm{mM}$ ammonium acetate, $0.1 \% \mathrm{TFA}$, and formic and acetic acid were purchased from Sigma-Aldrich. The GSH and GSSG standards were supplied by Sigma-Aldrich.

Analytical Techniques

\section{Gas Chromatography-Mass Spectrometry}

The first step was the derivatization of glutathione and analysis of $N, S$-ethoxycarbonyl methyl esters (NSECM) by the GC-MS method.

A total of $400 \mathrm{mg}$ of muscle tissues was homogenized in $1 \mathrm{~mL} 0.2 \mathrm{M}$ phosphate buffer with $0.6 \mu \mathrm{mol}$ of reduced GSH (internal standard) and $160 \mu \mathrm{mol}$ of dithiothreitol. Before derivatization, $2 \mathrm{~mL} 0.2 \mathrm{M}$ phosphate buffer was added. After homogenization, the $\mathrm{pH}$ was adjusted to 8.5 with $0.8 \mathrm{M} \mathrm{NaOH}$. The deproteinization process was adapted from Humbert et al. (2001) and Küster et al. (2008). The samples were deproteinized by the addition of $375 \mu \mathrm{L}$ TCA and $375 \mu \mathrm{L} 0.2 \mathrm{M}$ phosphate buffer, and the $\mathrm{pH}$ was adjusted to 7.5. The derivatization was affected by two processes: derivatization of the $-\mathrm{NH}_{2}$ and $-\mathrm{SH}$ groups and derivatization of the $-\mathrm{COOH}$ of glutathione.

In the first step, $200 \mu \mathrm{L}$ of ethylchloroformate was added, then the mixture was shaken for $15 \mathrm{~min}$ at room temperature. The $\mathrm{pH}$ was adjusted to 1.5 with $1 \mathrm{~mL} \mathrm{HCl}$; the mixture was then saturated with $0.5 \mathrm{~g} \mathrm{NaCl}$ and extracted two times with ethyl acetate (or peroxide-free diethyl ether). The organic phase was evaporated to dryness under nitrogen gas flux at $50^{\circ} \mathrm{C}$. The second step was derivatization of the $-\mathrm{COOH}$ groups of glutathione, then $250 \mu \mathrm{L}$ of $1 \mathrm{M} \mathrm{HCl}$ in methanol was added and the mixture was incubated for $10 \mathrm{~min}$ at $80^{\circ} \mathrm{C}$. After evaporation in a nitrogen gas flux, the residue was dissolved in $400 \mu \mathrm{L}$ ethyl acetate before GC-MS analysis. The glutathione was analyzed using a Finnigan Mat SSQ 710 mass spectrometer coupled to a Hewlett Packard 5890 gas chromatograph. The glutathione was separated in a $10 \mathrm{~m} \times 0.25 \mathrm{~mm}$ i.d. HP-5 MS capillary column (film thickness $0.25 \mu \mathrm{m}$ ) and chromatographic parameters were used for GC-MS as by Humbert et al. (2001).

\section{Matrix-Assisted Laser Desorption with Ionization Time-of-Flight}

Selection of a Suitable Matrix The second mass spectrometry technique to be used was MALDI-TOF with a reflectron (Bruker, Bremen, Germany). Preliminary assays were carried out with a standard solution using two matrices: DHB (2,5dihydroxybenzoic acid) and $\alpha$-HCCA ( $\alpha$-cyano-4-hydroxycinnamic acid). This way, the matrix was checked for the best type of chemical compounds. The spectra were recorded in the positive ion mode $\left([\mathrm{M}+\mathrm{H}]^{+},[\mathrm{M}+\mathrm{Na}]^{+}\right.$, and $\left.[\mathrm{M}+\mathrm{K}]^{+}\right)$with an accelerating voltage of $19 \mathrm{kV}$ and a reflective voltage of $20 \mathrm{kV}$. The MALDI-TOF was equipped with a pulsed $\mathrm{N}_{2}$ laser with a wavelength of $\lambda=337 \mathrm{~nm}$ and a delay time of $1500 \mathrm{~ns}$. The mass range in the MALDI-TOF spectra was from 200 to 
2000 a.m.u. The internal standards (GSH and GSSG) were homogenized in methanol and mixed with the DHB matrix and with $\alpha$-HCCA, separately, in a ratio of 1:1000. The prepared solutions were applied to a metal plate that was evaporated in an air stream to obtain a homogeneous mixture. Such prepared samples were subjected to MALDI-TOF/MS analysis (Bruker).

Selection of a Suitable Solvent The next step was to test a number of solvents used for the homogenization of biological material (internal standards were used originally) in order to choose the best solvent for the analysis of glutathione. Four solutions were prepared: $100 \%$ methanol, methanol/water (50:50) $(\mathrm{v} / \mathrm{v})$, methanol $+0.01 \%$ acetic acid, and ammonium buffer $\mathrm{pH} 3.5\left[\mathrm{H}_{2} \mathrm{O} / \mathrm{ACN}(90: 10)(\mathrm{v} / \mathrm{v})+1 \mathrm{mM}\right.$ $\left.\mathrm{NH}_{4}\left(\mathrm{CH}_{3} \mathrm{COO}\right)\right]$.

The internal standards were dissolved in $10 \mathrm{~mL}$ of each of these solutions and were analyzed by MALDI-TOF/MS.

Addition of Trifluoroacetic Acid to Maintain the Acidic Properties of the Analytes Based on the literature, an acidic environment positively impacts analytes (maintaining an acidic environment prevents the oxidation of GSH to GSSG); hence, the next stage of research was the addition of trifluoroacetic acid (TFA) to the analyzed samples. It was done to compare the results with and without the addition of TFA. The first sample was dissolved in methanol with $0.1 \mathrm{~mL}$ of $50 \%$ of the SSA and the second sample in an ammonium buffer pH $3.5\left[\mathrm{H}_{2} \mathrm{O} / \mathrm{ACN}(90: 10)(\mathrm{v} / \mathrm{v})+1 \mathrm{mM}\right.$ $\left.\mathrm{NH}_{4}\left(\mathrm{CH}_{3} \mathrm{COO}\right)\right]$ with $\mathrm{CH}_{3} \mathrm{COOH}$. To each sample, $0.1 \%$ of TFA acid was added and the sample was mixed with $1 \mu \mathrm{L}$ of the modified DHB matrix ( $\mathrm{v} / \mathrm{v}, 1: 1)$. After drying on a metal plate in an air stream, it was subjected to MALDI-TOF analysis. To check the positive properties of TFA in determining glutathione, the same sample was prepared with matrix DHB but without the addition of TFA.

All of the stages of determining glutathione using the MALDI-TOF/MS techniques were initially carried out on standard solutions of GSH and GSSG. The purpose was to reduce the loss of biological material and to adapt the procedure of glutathione determination.

\section{High Performance Liquid Chromatography-Tandem Mass Spectrometry}

The last technique applied to identify the form of reduced glutathione and oxidized glutathione as well as to quantify their distribution in the tissues of $C$. crangon was HPLC-MS/MS.

The first step was to determine the best chromatographic conditions for the analysis, the selection of a mobile phase, duration of analysis, the amount of sample to be analyzed, determination of the smallest detectable concentration of the analyte, retention time for GSH and GSSG, limit of detection and quantification, the choice of chromatographic column, and the selection of operating parameters of HPLC instrument (1200 series HPLC system; Santa Clara, USA). During the validation and optimization method, the internal standards dissolved in the four solvents were tested in a mixture of $100 \%$ methanol, methanol/water $(50: 50)(\mathrm{v} / \mathrm{v})$, methanol $+0.01 \%$ acetic acid, and ammonium buffer $\mathrm{pH} 3.5$ $\left[\mathrm{H}_{2} \mathrm{O} / \mathrm{ACN}(90: 10)(\mathrm{v} / \mathrm{v})+1 \mathrm{mM} \mathrm{NH}_{4}\left(\mathrm{CH}_{3} \mathrm{COO}\right)\right]$. The aim was to choose the best solvent for the homogenization of biological material, thus giving the best results of glutathione determination in biologically active components. The Kinetex $\mathrm{C}_{18}(100 \times 4.6 \mathrm{~mm}, 2.6 \mu \mathrm{m} 100 \mathrm{~A})$ column (Phenomenex, Torrance, USA) was used for chromatographic separation using $50 \%$ water (with the addition of $0.04 \%$ formic acid) as solvent $\mathrm{A}$ and $50 \%$ methanol as solvent $\mathrm{B}$. The flow rate was $0.3 \mathrm{~mL} \mathrm{~min}{ }^{-1}$, and $50 \mu \mathrm{L}$ was injected into the column. Oxidized and reduced glutathione was eluted by isocratic elution chromatography within $6 \mathrm{~min}$. The column was thermostated in a temperature of $25^{\circ} \mathrm{C}$. Detection was performed on a Bruker Daltonics HCT Ultra Ion Trap (Bremen, Germany). The HPLC system was connected to the MS via DAD. The nebulizer pressure was $30 \mathrm{psi}$, dry gas temperature was $350{ }^{\circ} \mathrm{C}$, and dry gas flow was $10 \mathrm{Lmin}^{-1}$. The capillary voltage was $-4 \mathrm{kV}$. The mass range in the MS spectra was from 100 to 700 a.m.u., and the amplitude of MS/MS fragmentation amounted to $1.00 \mathrm{~V}$. The instrument was run in positive ion mode with single ion monitoring (SIM) mode ( $\mathrm{m} / z 308$ for GSH and $\mathrm{m} / z 613$ for GSSG) as well as with multiple reaction monitoring (MRM) ( $\mathrm{m} / \mathrm{z}$ 162, $\mathrm{m} / \mathrm{z}$ 179, and $\mathrm{m} / \mathrm{z} 233$ for GSH; $\mathrm{m} / \mathrm{z} 355, \mathrm{~m} / \mathrm{z} 484$, and $m / z 595$ for GSSG).

This technique was the simplest and most rapid method to determine the internal standards; hence, after validation and optimization, glutathione in the biological samples was determined.

Three different species of marine organisms were collected for studying the glutathione content. These were turbot (Psetta maxima), herring (Clupea harengus membras), and brown shrimp (C. crangon). They were caught off the coastal area of the Gulf of Gdansk in July 2010 (turbot and Baltic herring) and from July 2010 to November 2011 (brown shrimp). The fish and shrimp were decapitated and their muscles were dissected and frozen at $-80{ }^{\circ} \mathrm{C}$ in glass tubes. The muscles, livers, and hepatopancreases (brown shrimp) were macerated and $0.25-0.35 \mathrm{~g}$ of tissue was taken for weighing and homogenization. The tissues were homogenized in $1 \mathrm{~mL}$ of ammonium buffer pH $3.5\left[\left(\mathrm{H}_{2} \mathrm{O} / \mathrm{ACN}(90: 10)(\mathrm{v} / \mathrm{v})+1 \mathrm{mM}\right.\right.$ $\mathrm{NH}_{4}\left(\mathrm{CH}_{3} \mathrm{COO}\right)$ with acetic acid]. 5,5'-Dithiobis-2-nitrobenzoic acid (DTNB) was added to each solution in order to protect the reduced glutathione thiol groups. Homogenates were centrifuged at $4000 \times \mathrm{g}$ for $10 \mathrm{~min}$. Then an ammonium buffer up to a volume of $1.5 \mathrm{~mL}$ was added to the supernatant. To determine the variability of results, they were compared 
with Student's $t$ test and were significant at $p<0.05$. The data are expressed as means \pm standard error (SE).

\section{Results}

When discussing glutathione in general, it is a determined component and is called an antioxidant, "glutathione", and only when considering the concentrations of various forms is it adopted as the abbreviation GSH.

\section{Analysis by Gas Chromatography-Mass Spectrometry}

Figure 1 presents the $N, S$-ethoxycarbonyl methyl esters of the glutathione standard. This technique required a large number of reagents and is very time consuming. Moreover, at various stages of sample preparation for GC-MS analysis, there is the risk of losing some determined component. Nevertheless, after identifying the standard, we wanted to mark the natural antioxidant in the biological sample, i.e., in the muscle tissue of $C$. crangon.

Figure 2 shows the chromatogram of an extract of the $C$. crangon muscle. The detection of characteristic ions for the $N, S$-ethoxycarbonyl methyl ester of reduced glutathione was used, but only the derivatives (NSECM) of cysteine and lysine, the products of glutathione degradation, were identified. The reason why there was a lack of glutathione in the biological sample was unknown. Different acids maintaining a low $\mathrm{pH}$ were checked, and reducing agents which do not lead to oxidation of reduced glutathione and a higher amount of the analytical sample were used to verify the true reason. Different biological materials were applied; however, none of these changes allowed for an identification of GSH in the biological samples.

\section{Analysis of Matrix-Assisted Laser Desorption Time-of-Flight Mass Spectrometry (MALDI-TOF/MS)}

Figures 3 and 4 present the application of MALDI-TOF/MS. Ammonium buffer $\mathrm{pH} 3.5$ was the best solvent for a qualitative identification. The intensity of the internal standards was significantly higher with the application of the DHB matrix. Simultaneously, the ions of the DHB matrix were much less intense than $\alpha$-HCCA, which was important in detecting the ions of reduced and oxidized glutathione. The ions of $\alpha$ HCCA had pointedly higher intensity than the intensity of the molecular ion $308 \mathrm{~m} / \mathrm{z}$ and $613 \mathrm{~m} / \mathrm{z}$ (Fig. 3).

In turn, the addition of $0.1 \%$ TFA at the stage of the standards study did not affect the intensity of signals. What is more, the dominant ion was $\left[\mathrm{M}+\mathrm{Na}^{+}\right]$, both for $\mathrm{GSH}$ and GSSG (Fig. 4). TFA acid was used to maintain a low pH and simultaneously to protect the thiol groups against oxidation. In the analysis with the use of the GSH standard, the addition of
TFA acid did not give the expected results. However, the TFA acid added to the biological sample probably reduced GSSG to a reduced form of glutathione because the intensity of the GSSG ions was very low for the sample with the addition of TFA (Fig. 4).

A direct analysis of the biological material (muscles of $C$. crangon) with the addition of TFA acid allowed to identify a higher intensity of GSH ions. TFA acid blocked the formation of GSSG, which resulted in a lower intensity of the observed GSSG ions (Fig. 5).

Analysis of HPLC Coupled with Tandem Mass Spectrometry (HPLC-MS/MS)

\section{Optimization of the Mobile Phase}

The first mobile phases were methanol (solvent A) and water (solvent B) in a linear gradient from $0 \%$ to $15 \%$ of methanol over $5 \mathrm{~min}$, with the isocratic stage holding at $15 \%$ methanol for $5 \mathrm{~min}$. The next mobile phases to be used were methanol (solvent A) and water with the addition of $0.1 \%$ TFA (solvent B), acetonitrile (solvent A) and water with the addition of $0.1 \%$ TFA (solvent B) as well as acetonitrile (solvent A) and water with the addition of $0.04 \% \mathrm{HCOOH}$ (solvent B). These phases were operated in isocratic flow $(50: 50, \mathrm{v} / \mathrm{v})$. Only methanol (solvent A) and $0.04 \%$ formic acid aqueous solution (solvent $\mathrm{B}$ ) in the isocratic flow gave satisfactory results. The standards were dissolved in ammonium buffer pH 3.5 since in previous studies the best results were obtained after such a solution was applied. An identical procedure was used in the biological material analysis.

\section{Linearity}

Eight concentrations of GSH and GSSG were prepared ( 0.005 , $0.025,0.01,0.05,0.1,0.5,1$, and $\left.5 \mathrm{ng} \mathrm{mL}^{-1}\right)$, respectively (Table 1). The regression equation was $f(x)=144,629,937.17 x-$ $7,664,162.17, R^{2}=0.999$ (Fig. 6). The regression curve for GSH and GSSG was the basis to calculate the content of reduced glutathione and oxidized glutathione in the biological samples (Fig. 6). The HPLC-MS/MS chromatogram presents specific MRM transitions of reduced glutathione IS (Fig. 7). These were $\mathrm{m} / \mathrm{z} 308 \rightarrow 162, \mathrm{~m} / \mathrm{z} 308 \rightarrow 179$, and $\mathrm{m} / \mathrm{z} 308 \rightarrow 233$ with a retention time of $5.3 \mathrm{~min}$ for every transition. For oxidized glutathione, the MRM transitions were $\mathrm{m} / \mathrm{z} 613 \rightarrow$ $355, \mathrm{~m} / z 613 \rightarrow 484$, and $m / z 613 \rightarrow 595$ with a retention time of 5.0 min for every transition (data not shown).

\section{Limit of Detection (LOD) and Quantification (LOQ)}

Limit of detection (LOD) was determined on the basis of parameters of the calibration curve for internal standards and was expressed as: $\mathrm{LOD}=3.3 \mathrm{SD} S^{-1}$, where $S$ is the 

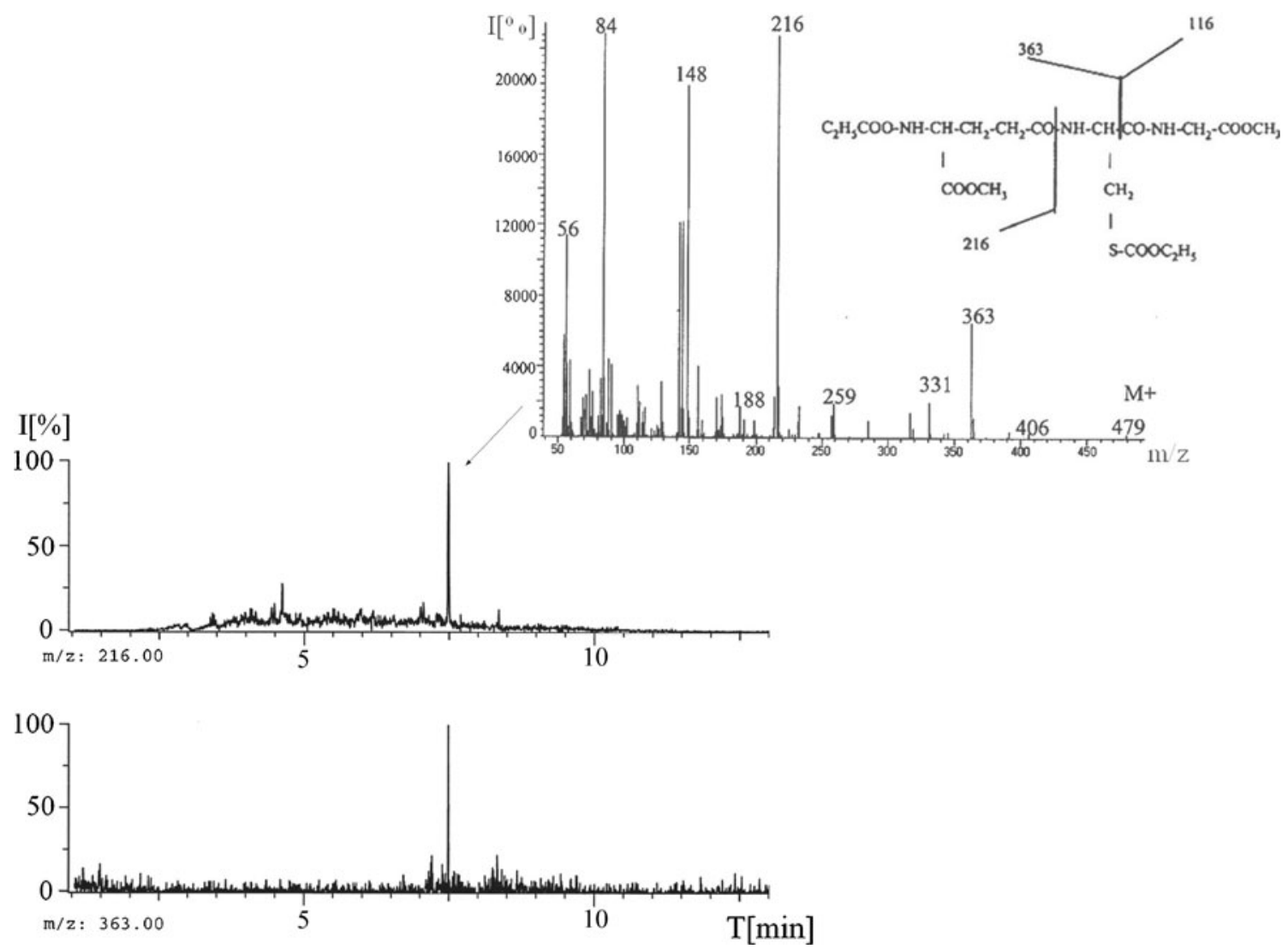

Fig. 1 Selected ion monitoring profiles of the $N, S$-ethoxycarbonyl methyl ester of the GSH internal standard and mass spectra

slope of the calibration curve and SD is the standard deviation of the response.

Limit of detection was $0.64 \mathrm{pg} \mathrm{mL}^{-1}$ for GSH and $4.59 \mathrm{pg} \mathrm{mL}^{-1}$ for GSSG.

Limit of quantification (LOQ) was expressed as: $\mathrm{LOQ}=$ $10 \mathrm{SD} \mathrm{S}^{-1}$, where $S$ is the slope of the calibration curve and $\mathrm{SD}$ is the standard deviation of the response.

Limit of quantification was $1.92 \mathrm{pg} \mathrm{mL}^{-1}$ for GSH and $13.76 \mathrm{pg} \mathrm{mL}^{-1}$ for GSSG.

\section{Precision and Recovery}

Precision (\% RSD) and recovery were studied for five measurements for a particular concentration. The mean precision and recovery were calculated for eight prepared concentrations of standard solutions. The mean precision was $0.60 \%$ and the mean recovery was $100.38 \%$.

\section{Determination of Glutathione in the Marine Tissues}

The GSH content in various tissues, different marine organisms, and various times of the year was determined. Three different taxons were studied: P. maxima inhabiting the sea bottom, $C$. harengus membras occurring in the open water of the sea, and C. crangon inhabiting the bottom of shallow coastal water. Concentrations of total, reduced, and oxidized glutathione were calculated on the basis of linearity of standard solutions (Table 1 and Fig. 6). The values of particular forms of glutathione from the marine taxon tissues were the means of five assays $(n=5)$.

Figure 8 and Table 2 present the marine taxons, their muscles, livers, and gonads collected during the same season (July 2010). The gonads of C. crangon were not collected due to the small size of the brown shrimp. The highest concentration of total glutathione and reduced glutathione was noted in the liver (hepatopancreas of brown shrimp) for the three tested organisms. The values for total glutathione were $1.377 \pm 0.0021 \mathrm{mg} \mathrm{g}^{-1}, 0.543 \pm 0.0047 \mathrm{mg} \mathrm{g}^{-1}$, and $0.355 \pm 0.0121 \mathrm{mg} \mathrm{g}^{-1}$ wet weight for the hepatopancreas of $C$. crangon and the liver of $C$. harengus membras and P. maxima, respectively (Fig. 8). The content of reduced glutathione in the liver (hepatopancreas) was $1.364 \pm$ $0.0021 \mathrm{mg} \mathrm{g}^{-1}, 0.542 \pm 0.0047 \mathrm{mg} \mathrm{g}^{-1}$, and $0.352 \pm$ $0.0119 \mathrm{mg} \mathrm{g}^{-1}$ for brown shrimp, Baltic herring, and turbot, respectively. The total and reduced glutathione content also dominated in the gonad, but only in P. maxima, and in the muscle tissue of $C$. harengus membras. The content of tGSH and GSH in the Baltic herring was significant for particular organs, much more than the content of tGSH and GSH in the organs of turbot. The highest content of 

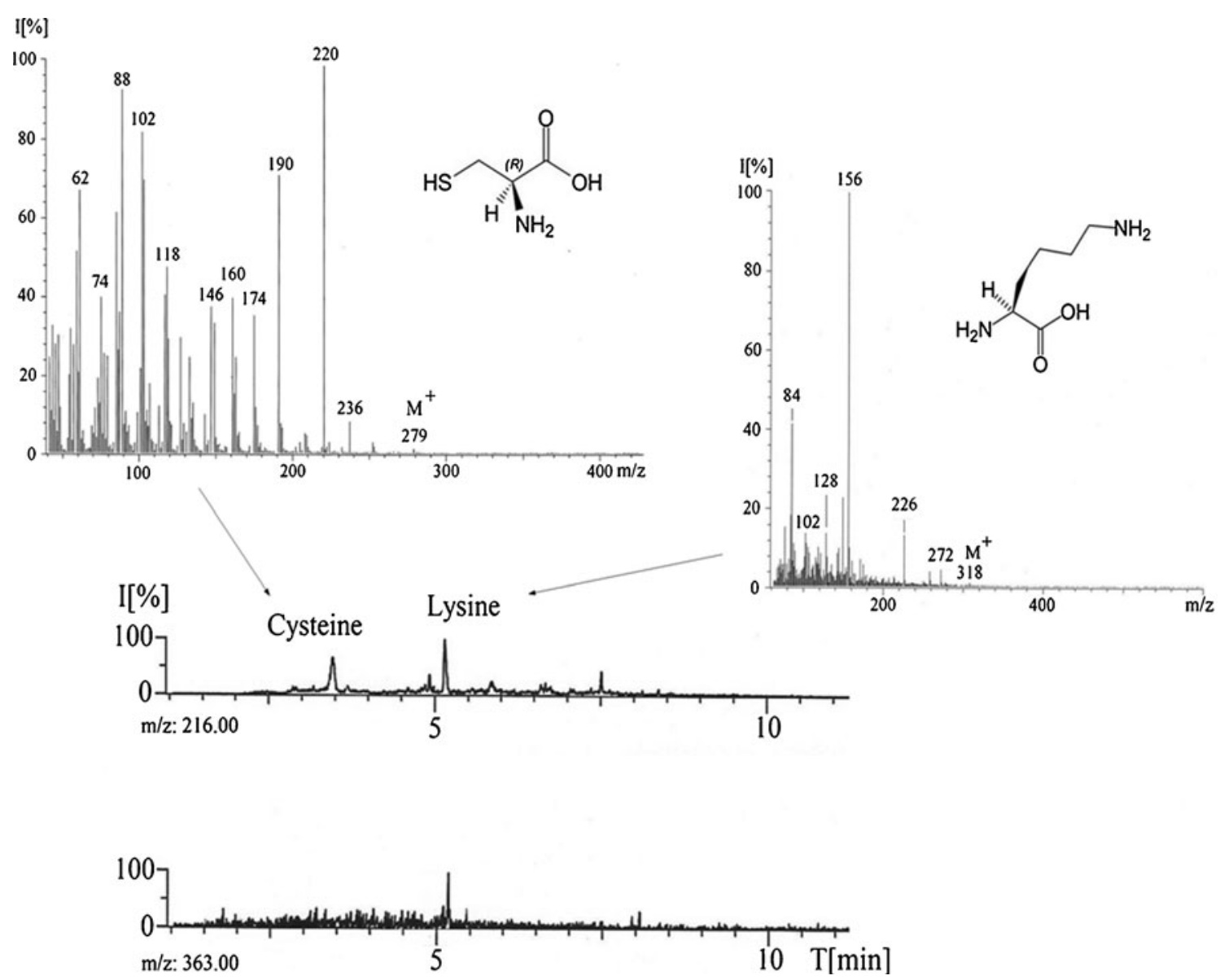

Fig. 2 Chromatogram of the GC-MS total ion current and mass spectra of the $N, S$-ethoxycarbonyl methyl ester of cysteine and lysine, derived from Crangon crangon muscle

glutathione was noted in brown shrimp tissues. The content of GSH in the muscle was two to four times higher than in their organisms, and 2.5 to four times higher in the hepatopancreas. The tissues of C. crangon varied considerably in the content of GSH. A reduced glutathione content in the hepatopancreas was almost 1.4 times higher than in the muscle of brown shrimp (Fig. 8).

The GSSG content in the muscle of brown shrimp was significantly higher than in the hepatopancreas, similarly as in turbot muscle and liver. Smaller differences between the muscle and liver were noted in herring tissues. Clearly, the GSSG value in fish gonads was higher than in the muscles (Table 2). Additionally, concentrations of glutathione were measured in herring spermatozoa. The content of tGSH, GSH, and GSSG was $0.44 \pm 0.006 \mu \mathrm{mol} \mathrm{g}^{-1}, 0.44 \pm 0.006 \mu \mathrm{mol} \mathrm{g}^{-1}$, and $0.0001 \pm 0.000001 \mu \mathrm{mol} \mathrm{g}^{-1}$ wet weight, respectively (Table 2).

When comparing fish tissue, significantly higher concentrations of GSSG were observed in turbot. The value of GSSG in gonads was $0.063 \pm 0.000170 \mu \mathrm{mol} \mathrm{g}^{-1}$ and $0.009 \pm 0.000015 \mu \mathrm{mol} \mathrm{g}^{-1}$ wet weight for P. maxima and $C$. harengus membras, respectively. In the muscles, the
GSSG content was $0.040 \pm 0.000264 \mu \mathrm{mol} \mathrm{g}{ }^{-1}$ for turbot and $0.008 \pm 0.000013 \mu \mathrm{mol} \mathrm{g}^{-1}$ for herring. The lowest concentrations of oxidized glutathione were noted in the liver and amounted to $0.008 \pm 0.000272 \mu \mathrm{mol} \mathrm{g}{ }^{-1}$ in turbot liver and $0.005 \pm 0.000044 \mu \mathrm{mol} \mathrm{g}^{-1}$ in herring liver (Table 2). Similar results were noted for tGSH and GSH (Table 2), which were presented in Fig. 8 (in milligrams of glutathione per $1 \mathrm{~g}$ of tissue for different organisms).

The next aim was to determine the seasonal variations in total, reduced, and oxidized glutathione content in the muscle of brown shrimp. C. crangon was chosen because of its availability throughout the year and because it is not subjected to protective periods. Moreover, the analysis of glutathione in different organisms showed the highest concentration of different types of glutathione in C. crangon. The content of tGSH, GSH, and GSSG in the muscle of brown shrimp was studied from July 2010 to November 2011. Similarly as in the previous study, the concentration of total, reduced, and oxidized glutathione was calculated on the basis of the linearity of standard solutions (Table 1 and Fig. 6). The values of particular forms of glutathione from the tissues of marine taxons were the means of five assays $(n=5)$. 
Fig. 3 MALDI-TOF/MS

mass spectra of 1) GSH

and 2) GSSG in a DHB and

b matrix $\alpha$-HCCA
1)

a)

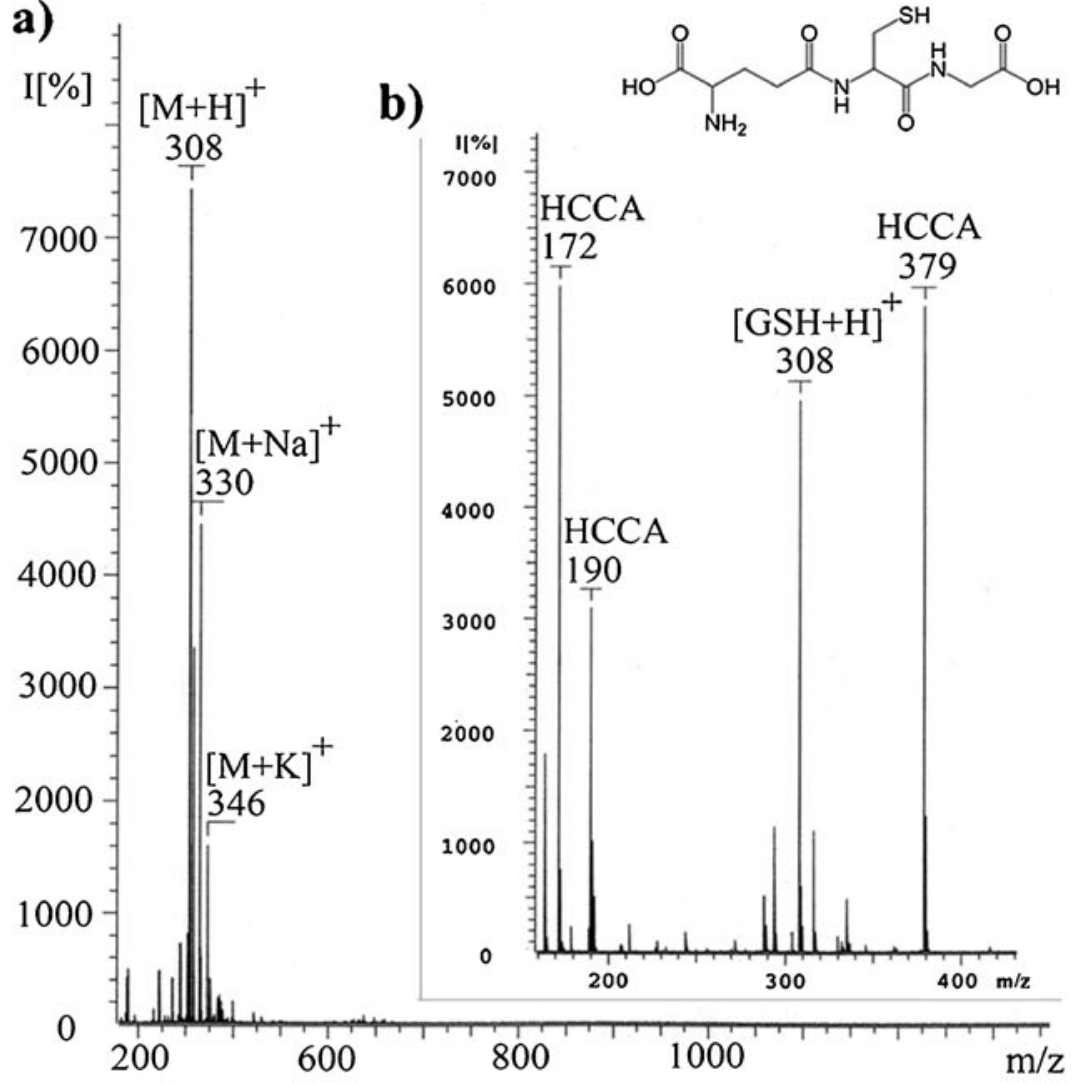

2)

a)

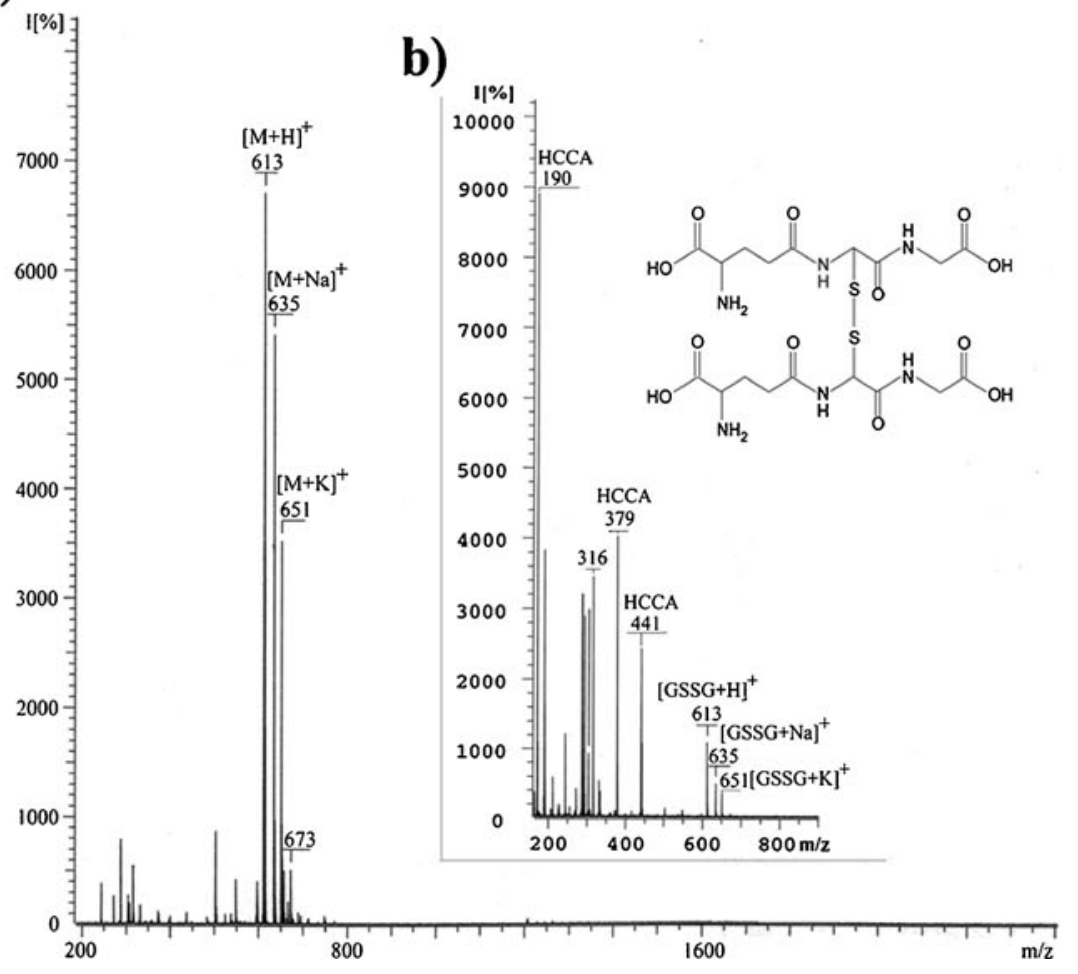


Fig. 4 MALDI-TOF/MS

mass spectra of 1) GSH and 2)

GSSG a without TFA and $\mathbf{b}$

with addition of TFA

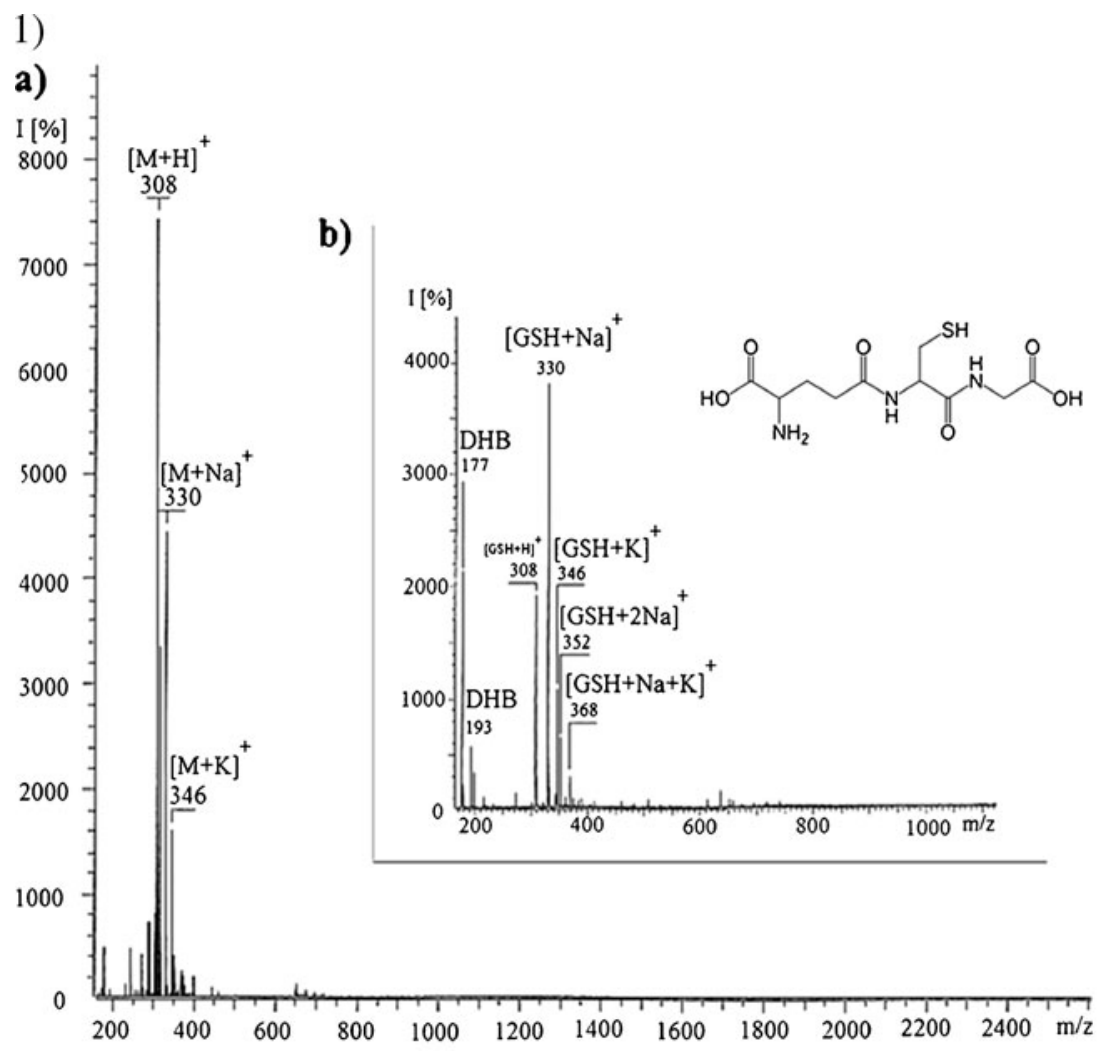

2)

a)

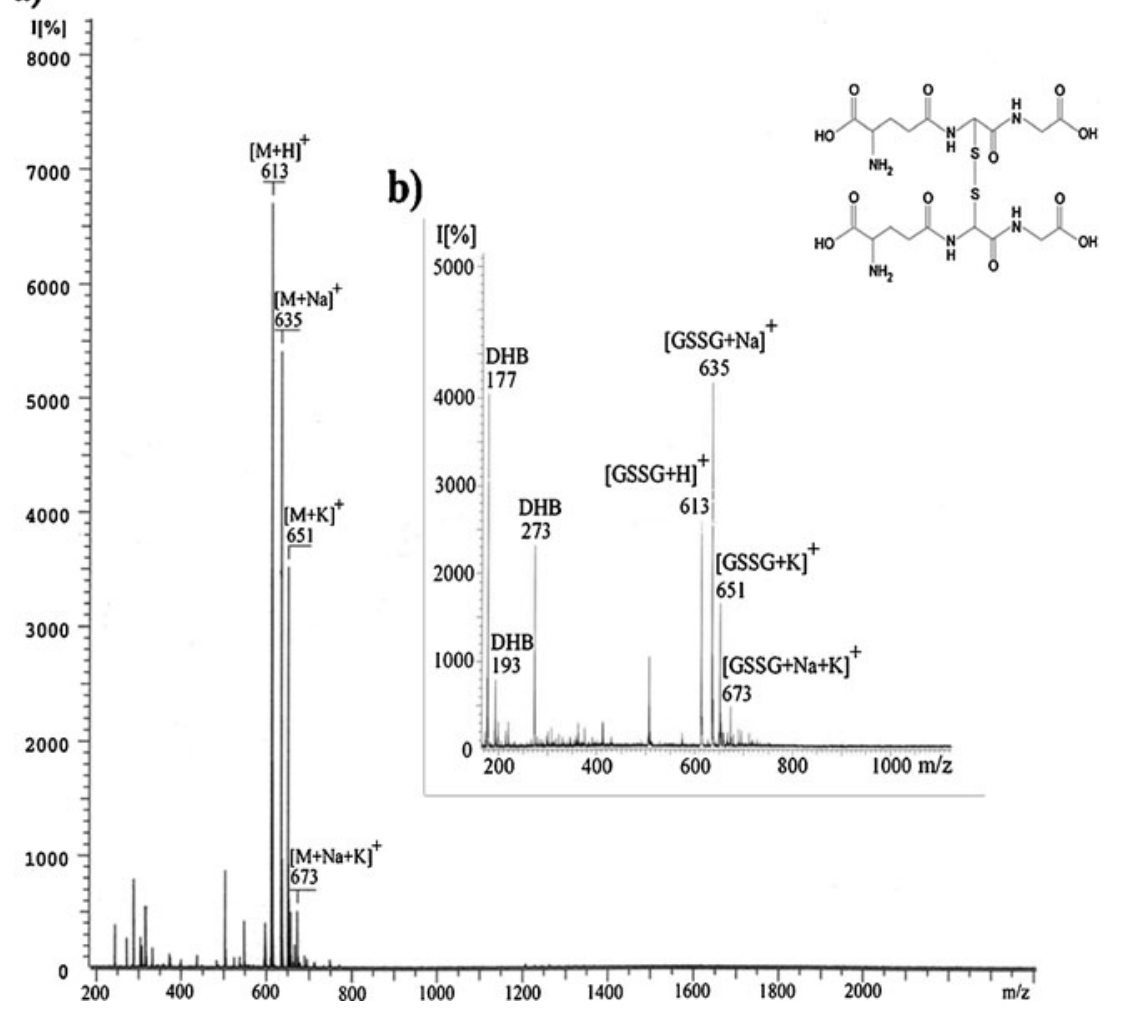

The glutathione content in the muscle of C. crangon The highest values were reported in July 2011, both for tGSH changed quite considerably in particular months (Fig. 9). and GSH, despite the fact that in previous years they were 
1)

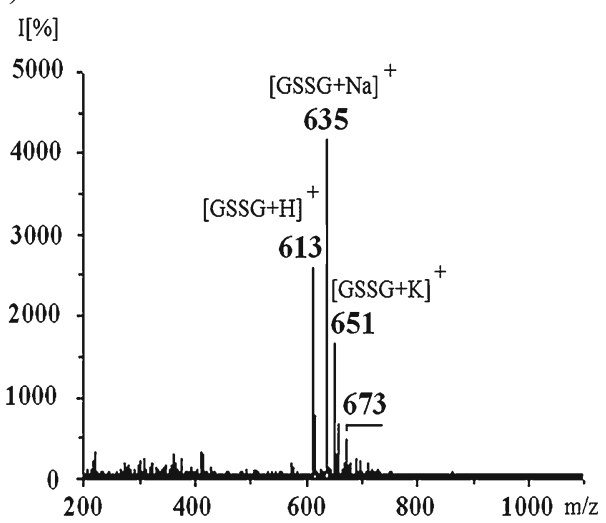

2)

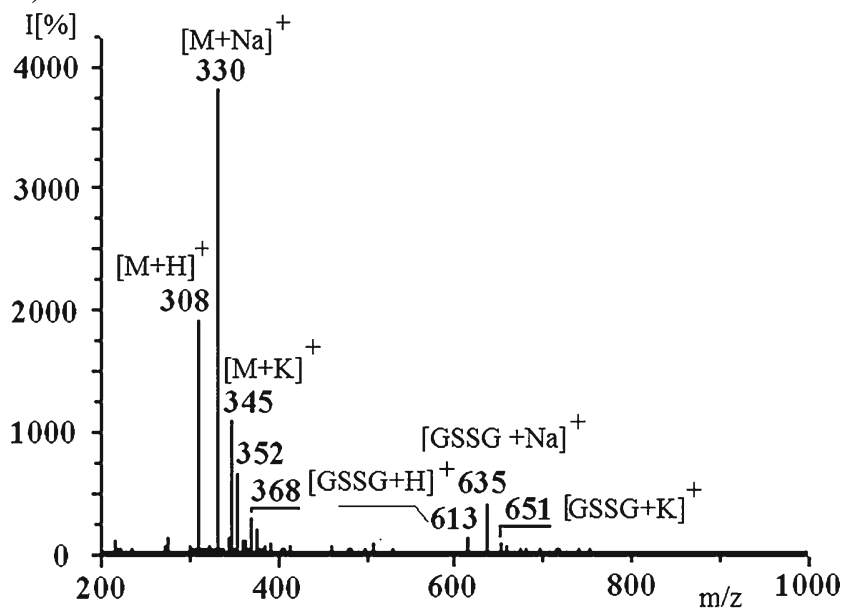

Fig. 5 MALDI-TOF/MS mass spectra of reduced and oxidized glutathione from the muscle of Crangon crangon in the DHB matrix. 1) Absence of $0.1 \%$ TFA, 2) addition of $0.1 \%$ TFA. Biological material was homogenized in ammonium buffer, $\mathrm{pH} 3.5$

much lower. From July to September 2010, the value of tGSH and GSH decreased, with a subsequent increase in GSH content, which was substantial from June to July 2011. After this period, the rapid decline was recorded for September

Table 1 Exposure limits of the scope of GSH for which the regression curve was plotted, precision, recovery, and standard deviation (SD)

\begin{tabular}{llcc}
\hline $\begin{array}{l}\text { Concentration } \\
\left(\mathrm{ng} \mathrm{mL} \mathrm{mL}^{-1}\right)\end{array}$ & $\mathrm{SD}$ & $\begin{array}{l}\text { Precision } \\
(\% \mathrm{RSD})\end{array}$ & Recovery (\%) \\
\hline 0.005 & 0.000028 & 0.52 & 107 \\
0.025 & 0.00007 & 0.64 & 114 \\
0.01 & 0.0002 & 0.70 & 110 \\
0.05 & 0.0001 & 0.19 & 104 \\
0.1 & 0.0004 & 0.41 & 94 \\
0.5 & 0.00747 & 1.87 & 80 \\
1 & 0.00409 & 0.44 & 94 \\
5 & 0.0015 & 0.03 & 100 \\
\hline
\end{tabular}

The number of measurements was five $(n=5)$

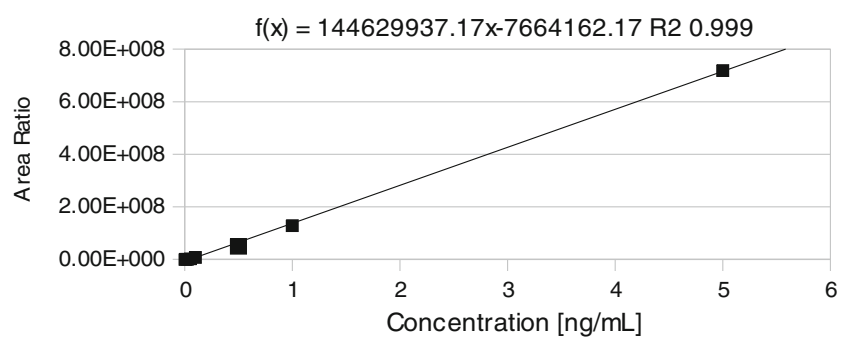

Fig. 6 Regression curve for GSH

2011, and another increase was in November 2011. Such variations might result in the oxidation of reduced glutathione to GSSG, but as is shown in Fig. 9, the content of total and reduced glutathione ranged in the earlier periods of investigations. However, we did not exclude the oxidation of GSH. The results for GSH and GSH were positively correlated, whereas in the case of GSSG a negative correlation was observed. The increase in the reduced form of glutathione caused a decrease in the amount of GSSG and inversely (Fig. 9).

Table 3 presents the concentration of total, reduced, and oxidized forms of glutathione which was measured in the muscle of brown shrimp. In September 2010 and 2011, the concentration of tGSH and GSH was very similar. The highest concentrations of tGSH were noted in the summer of 2011 and during late autumn. These were $12.60 \pm 0.215 \mu \mathrm{mol} \mathrm{g}^{-1}$ and $7.90 \pm 0.167 \mu \mathrm{mol} \mathrm{g}^{-1}$ wet weight, respectively. In turn, the highest concentrations for GSSG were in September 2010 $\left(0.68 \pm 0.0027 \mu \mathrm{mol} \mathrm{g}^{-1}\right)$, when tGSH and GSH were recorded in the lowest contents. During this season, the GSH/GSSG ratio was the lowest (Table 3).

\section{Discussion}

\section{A Short Analysis of Applicable MS Techniques}

The aim of this study was to determine the presence of glutathione by using mass spectrometry techniques. The next purpose was to determine concentrations of glutathione in various tissues of marine organisms as well as the seasonal variability of the GSH concentration in the muscle of $C$. crangon. GC-MS, MALDI-TOF/MS, and HPLC-MS/MS techniques were tested as the best techniques for glutathione analysis.

The first technique to be used was GC-MS. The procedures according to Humbert et al. (2001), which were also used by Küster et al. (2008), helped to determine the reduced glutathione standard (Fig. 1). However, the analysis of the biological material did not reach expected results. Cysteine, a synthetic precursor of GSH (Guan et al. 2003), and lysine, an amino acid essential for the construction of proteins in skeletal muscle (Tanphaichitr et al. 1971), were identified. The reason could be a small amount of the sample, too low or too high 
Fig. 7 Mass chromatogram of the standard sample (GSH) in positive ion mode with multiple reaction monitoring (MRM), spiked with $5 \mathrm{ng} \mathrm{mL}^{-1}$

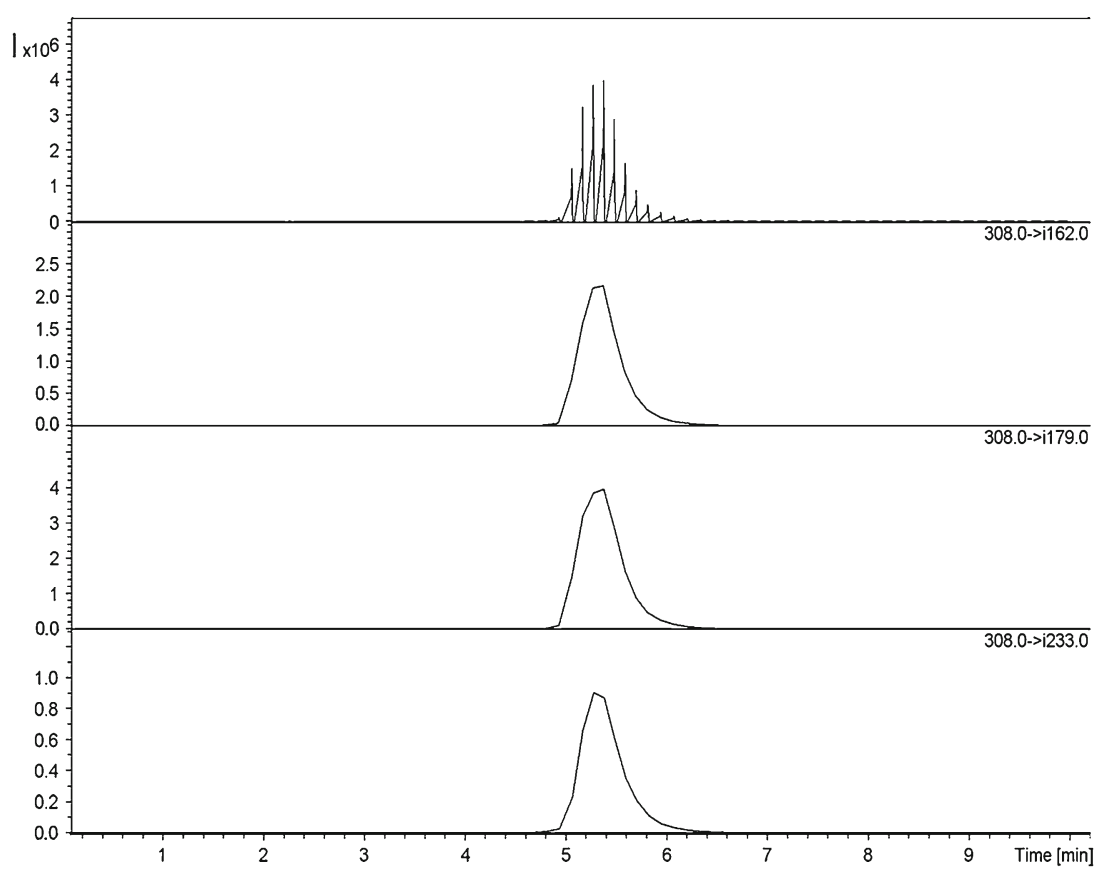

environmental $\mathrm{pH}$, or loss of the determined component during the long and complicated process of sample preparation before analysis of GC-MS. Therefore, the next sample had an increased amount of biological material. During the whole preparation process, the $\mathrm{pH}$ was checked, and recommended amounts of reagents were added. The result was always the same (Fig. 2). It is probable that the amount of glutathione in the biological material was lower than the limit of GC-MS detection and quantification.

The next technique to be used was MALDI-TOF/MS. We tested two matrices: DHB (2,5-dihydroxybenzoic acid) and $\alpha$ HCCA ( $\alpha$-cyano-4-hydroxycinnamic acid), and different solvents of the analyzed compounds. The HCCA matrix was used by Kato et al. (2003) to determine glutathione conjugated with allergenic components. The intensity of the searched conjugates was significantly lower than the HCCA matrix ions (Kato et al. 2003). The DHB matrix gave the best results for determining GSH and GSSG (Fig. 3). The peaks of particular ions were much more intense than in the application of the HCCA matrix. The procedure by Mitamura et al. (2007) was used, and a great intensity for molecular ions $(\mathrm{m} / \mathrm{z} 308$ and 613 ) and protonated ions, $[\mathrm{M}+\mathrm{Na}]^{+}$and $[\mathrm{M}+\mathrm{K}]^{+}$, was noted. Trifluoroacetic acid was added to the DHB matrix to preserve a lower $\mathrm{pH}$ and to protect the thiol groups from oxidation. But perhaps, the $\mathrm{pH}$ was too low, so decrease in the intensity of the peak was noted (Fig. 4). Generally, the application of this method in order to determine two forms of glutathione in the biological sample gave very good results. Many authors suggested that the soft ionization technique, such as LC-MS and MALDI-TOF/MS, is adapted and recommended for determining complex biological compounds, although the MALDI-TOF/MS technique is not recommend for quantitative analysis (Kato et al. 2003; Pastore et al. 2003; Mitamura et al. 2007). Therefore, HPLC-MS/MS was used for this purpose. The validation and optimization method was time consuming, but after fulfilling these conditions for the calibration solutions of GSH and GSSG, this technique was the best for the quantitative and qualitative determination of
Fig. 8 Concentration of total and reduced glutathione in the gonad, muscle, and liver of Psetta maxima, Clupea harengus membras, and Crangon crangon. Values of tGSH and GSH were detected by HPLC-MS/MS

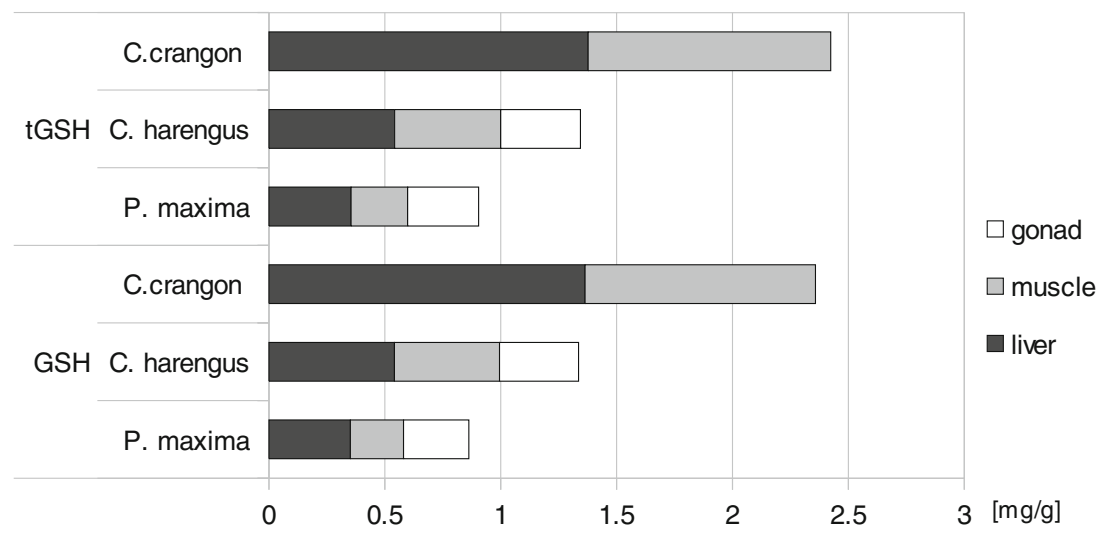


Table 2 The concentration ( $\mu \mathrm{mol} \mathrm{g}^{-1}$ wet weight) of total glutathione, reduced glutathione, and oxidized glutathione in particular tissues of shrimp and fish $(n=5)$

\begin{tabular}{lcll}
\hline & tGSH & GSH & GSSG \\
\hline C. crangon & & & \\
Hepatopancreas & $7.21 \pm 0.011$ & $7.16 \pm 0.011$ & $0.021 \pm 0.000032$ \\
Muscle & $5.50 \pm 0.094$ & $5.22 \pm 0.089$ & $0.140 \pm 0.000204$ \\
P. maxima & & & \\
Liver & $1.86 \pm 0.063$ & $1.85 \pm 0.063$ & $0.008 \pm 0.000272$ \\
Muscle & $1.28 \pm 0.008$ & $1.21 \pm 0.008$ & $0.040 \pm 0.000264$ \\
Gonad & $1.61 \pm 0.004$ & $1.48 \pm 0.004$ & $0.063 \pm 0.000170$ \\
C. harengus membras & & \\
Liver & $2.85 \pm 0.025$ & $2.84 \pm 0.025$ & $0.005 \pm 0.000044$ \\
Muscle & $2.40 \pm 0.004$ & $2.38 \pm 0.004$ & $0.008 \pm 0.000013$ \\
Gonad & $1.81 \pm 0.003$ & $1.79 \pm 0.003$ & $0.009 \pm 0.000015$ \\
Spermatozoa & $0.44 \pm 0.006$ & $0.44 \pm 0.006$ & $0.0001 \pm 0.000001$ \\
\hline
\end{tabular}

glutathione in the biological samples. The significant intensity of the signals of calibration solutions was at a level of concentration of pictograms per milliliter (Table 1, Figs. 6 and 7). Mean precision and recovery were at a high level of detection, $100.38 \%$ and $0.60 \%$, respectively. European recommendations for determination of compounds are 80-120\% for recovery, and acceptable precision is $2.68 \%$ (Miszczyk 2007); for other compounds, it can be up to $5 \%$ (Green 1996). The limit of detection was below $1 \mathrm{pg} \mathrm{mL}^{-1}$ for GSH and $4.59 \mathrm{pg} \mathrm{mL}^{-1}$ for GSSG. Some authors also noted significant differences in LOD for GSH and GSSG (Camera and Picardo 2002). It is surprising that the technique of LC-MS characterizes the detection limit below $0.1 \mathrm{pg} \mu \mathrm{L}^{-1}$, where the LOD for the GC-MS technique with derivatization is a value above $100 \mathrm{pg} \mathrm{\mu L}^{-1}$ (Hottenroth et al. 2000).

Determination of Total, Reduced, and Oxidized Glutathione in the Biological Samples

The study's aim was to develop a method of HPLC-MS/MS to measure glutathione without the derivatization process and to determine concentrations in different tissues of marine organisms. The liver and hepatopancreas were chosen for the studies because they are responsible for regulating the
Table 3 Total (tGSH), reduced (GSH), and oxidized (GSSG) content in the muscle of C. crangon

\begin{tabular}{lrrl}
\hline & \multicolumn{3}{l}{ Concentration of glutathione $\left(\mu \mathrm{mol} \mathrm{g} \mathrm{g}^{-1}\right.$ wet weight $)$} \\
\cline { 2 - 4 } & \multicolumn{1}{l}{ tGSH } & \multicolumn{1}{l}{ GSH } & \multicolumn{1}{l}{ GSSG } \\
\hline July & $5.89 \pm 0.039$ & $4.90 \pm 0.033$ & $0.50 \pm 0.0033$ \\
September & $5.32 \pm 0.021$ & $3.96 \pm 0.016$ & $0.68 \pm 0.0027$ \\
June & $6.39 \pm 0.088$ & $5.45 \pm 0.075$ & $0.47 \pm 0.0064$ \\
July & $12.60 \pm 0.215$ & $12.50 \pm 0.214$ & $0.05 \pm 0.0008$ \\
September & $5.99 \pm 0.053$ & $5.19 \pm 0.046$ & $0.39 \pm 0.0034$ \\
November & $7.90 \pm 0.167$ & $7.63 \pm 0.162$ & $0.14 \pm 0.0029$ \\
\hline
\end{tabular}

The number of measurements was $5(n=5)$

metabolism and for detoxification of xenobiotics (Muriana et al. 1993); the muscles are used for the purpose of consumption, and gonads and spermatozoa (only herring) because of the large amounts of xenobiotics, including heavy metals, affecting their biological activity (Napierska et al. 1997).

GSH is synthesized in the liver, which is the main reservoir for this antioxidant (Hjeltnes et al. 1992); therefore, the largest concentrations of total and reduced glutathione were noted in the liver and the hepatopancreas and were in a range from $7.21 \pm 0.011 \mu \mathrm{mol} \mathrm{g}^{-1}$ wet weight in hepatopancreas of $C$. crangon, $1.86 \pm 0.063 \mu \mathrm{mol} \mathrm{g}^{-1}$ in the liver of $P$. maxima, and $2.85 \pm 0.025 \mu \mathrm{mol} \mathrm{g}^{-1}$ in the liver of $C$. harengus membras (Table 2). This is consistent with data provided by $\mathrm{Ji}$ and Leeuwenburgh (1995), who noted a GSH concentration of about 5-7 $\mathrm{mM}$ in the liver. Larger concentrations of tGSH and GSH in the liver than in the muscle tissues were also recorded in three species of crayfish studied by Kovačević et al. (2008). Similar concentrations of GSH in the fish liver were recorded by Hjeltnes et al. (1992) in the liver of salmon with pathogenic changes. A significant influence on the concentration of GSH and the ratio of GSH/GSSG is caused by the presence of cadmium in the habitat of marine organisms as well as by organic pollutants. Toxic substances initially increase the concentration of GSH as the organism's immune response ( $\mathrm{Li}$ et al. 2010; Kovačević et al. 2008), but finally the GSH content decreases (Kovačević et al. 2008). Oxidative stress, which is initiated by free radicals (FR) and reactive oxygen species (ROS) promoting lipid peroxidation and oxidation of GSH to
Fig. 9 Seasonal variations in total, reduced, and oxidized glutathione, detected in the muscle of Crangon crangon by HPLC-MS/MS

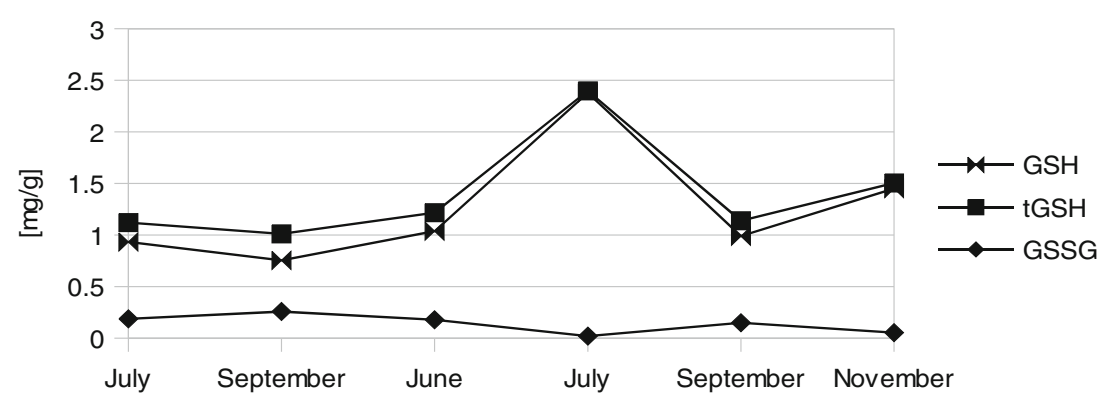


form GSSG, contributes to the reduction of this important molecule and the change in the ratio of GSH/GSSG of 100:1 to $10: 1$ or even $1: 1$ (Pastore et al. 2003). Therefore, this results in the differences in the liver of the two analyzed fish species. Peña-Llopis et al. (2002) also noted that the concentration of GSH in the liver and muscle decreases with time of exposure to toxic substances.

Small concentrations of GSSG were recorded for each tested tissue, which is the correct result because GSSG represents about $1 \%$ of GSH (Ji and Leeuwenburgh 1995). Similar as to the studies conducted by Kovačević et al. (2008), the largest quantities of GSSG were recorded in the muscles and gonads, and the lowest in the liver and hepatopancreas. Conditions such as the presence of xenobiotics or stress could transform GSH to GSSG (Kovačević et al. 2008). These conditions probably contributed to the significant concentration of GSSG in the shrimp and turbot tissues. The $C$. crangon body is relatively very small compared to the fish organism, and the difference in the content of GSSG could be higher. Similarly as with the habitat of $P$. maxima, it may be essential for a larger content of the oxidized form of glutathione. This fish lives at the bottom, buried in the sand, where the concentration of accumulated xenobiotics is probably larger than in the water column. However, three marine species were compared inhabiting various habitats with different exposure to various physical-chemical conditions (Filho 1996). Therefore, the concentrations of the analyzed compounds may vary, and more information about the impact of the habitat on the tested taxon can be obtained by studying a few organisms from one habitat.

Another part of the work involved the seasonal variability of total, reduced, and oxidized glutathione in the muscle of C. crangon. Crustaceans are exposed to daily and seasonal fluctuations in the temperature and concentration of dissolved oxygen (Filho 1996; Power and Sheehan 1996). They constantly have to accommodate the terms of the habitat. Crustaceans, due to the wide range of occurrence, sensitivity to xenobiotics (mainly heavy metals and organic pollutants), ability to accumulate and availability throughout the year, can be used as biomarkers in environmental monitoring (Schilderman et al. 1999). The results of measurement of glutathione concentration very clearly show the seasonal variations. Moreover, GSH production in tissues is not constant. It is regulated by several enzymes and depends on the activity of glutathione reductase (Kovačević et al. 2008). High concentrations of GSH may be caused by increased volumes of cysteine or glutamine (Humbert et al. 2007), and toxic substances inhibit certain enzymes (FanjulMoles et al. 2009). Additionally, heavy metals involve high risk because they are a very serious factor which can interfere in cellular homeostasis (Bjerregaard and Christensen 1993). For example, the cadmium concentration in the muscle of $C$. crangon from the Gulf of Gdansk is 10 times higher than in the muscles of Palaemon serratus from Concarneau Bay (Napierska et al. 1997). The reduced amount of glutathione may lead to growth of metal cytotoxicity. In turn, the high concentrations of xenobiotics and low concentrations of GSH may cause the liver to reduce its capacity to detoxify (Hjeltnes et al. 1992).

The highest differences in glutathione concentrations were during autumn 2010 and 2011, which gave a lower GSH/GSSG ratio. This may indicate the effects of adverse, external conditions on cellular homeostasis or disorders of the internal functioning of the organism (Pastore et al. 2003; Kovačević et al. 2008). Power and Sheehan (1996), who studied seasonal changes in the concentration of antioxidants in the digestive gland and gills of Mytilus edulis, noted the highest concentration of glutathione in July and an increase in the GSH content in November as well as some of the lowest concentrations in June and September. According to these authors, the decrease in the amount of GSH was connected with the increase of lipid peroxidation and oxidative stress (Power and Sheehan 1996). These conclusions are confirmed by Anto et al. (2009), who studied the activity of antioxidant enzymes and increase in the intensity of lipid peroxidation (LP) in the muscles of crustaceans, Aristeus antennatus and Nephrops norvegicus. Anto et al. (2009) observed the highest value of LP during the spring and autumn, which may explain the low GSH concentration in these months in the muscle of $C$. crangon.

Glutathione is a very sensitive tripeptide that is dependent on many external and internal factors which determine its concentrations in different tissues of the organism, in different living environments and different periods of the year. The study on determining concentrations of two forms of glutathione in the tissues of species from the Baltic Sea is the first work in this field of science in this geographical region. We have provided information about the change in glutathione concentration in various tissues of animals inhabiting other habitats as well as information about seasonal changes of total, reduced, and oxidized glutathione in the muscle of shrimp. To fully confirm the above statements, research on the GSH concentration in other tissues is still being conducted, and changes in the annual cycle of content of glutathione of the listed species of fish will be tracked.

\section{Conclusions}

1. Several techniques of mass spectrometry were used to determine the qualitative and quantitative concentrations of glutathione. These were mass spectrometry connected with gas chromatography (GC-MS), matrixassisted laser desorption with ionization time-of-flight (MALDI-TOF/TOF), and mass spectrometry connected with liquid chromatography (HPLC-MS/MS). 
2. For the quantitative determination of glutathione, HPLCMS/MS was the best. The analysis time lasted $6 \mathrm{~min}$. We detected very low glutathione concentrations in the range of glutathione standards from 0.005 to $5.0 \mathrm{ng} \mathrm{mL}^{-1}$.

3. Many conditions, including physical-chemical, habitat, diet, age, heavy metals, xenobiotics, and pollutants, influence the GSH and GSSG concentrations. Therefore, these organisms, especially crustaceans, can be used as biomarkers in monitoring the marine environment.

4. This was the first time when species from the Baltic Sea were analyzed for the presence and concentration of glutathione.

5. The highest concentrations of glutathione were noted in the liver and hepatopancreas because these are organs producing an antioxidant, and an increased amount of GSH may indicate a significant contamination of the habitat. In turn, in an annual cycle the highest values of GSH were recorded in the summer, which is associated with antioxidant enzyme activities and with increased lipid peroxidation.

6. It is recommended that GSH be determined in other tissues of tested species and that the concentration of GSH be determined during the year of the listed species of fish in order to learn more about this process and to determine the exact reasons for these findings.

Acknowledgment Financial support was provided by the Polish Ministry of Research and Higher Education under grants 538-L1650802-12 and DS 8110-4-0085-1.

Open Access This article is distributed under the terms of the Creative Commons Attribution License which permits any use, distribution, and reproduction in any medium, provided the original author(s) and the source are credited.

\section{References}

Anto M, Arnau S, Buti E, Cortijo V, Gutiérrez E, Solé M (2009) Ecotoxicol Environ Saf 72:1455-1462

Balzer I, Espinola IR, Fuentes-Pardo B (1997) Biol Cell 89:539-543

Bjerregaard P, Christensen L (1993) Mar Ecol Prog Ser 99:271-281

Bouligand J, Deroussent A, Paci A, Morizet J, Vassal G (2006) J Chromatogr B 832:67-74

Camera E, Picardo M (2002) J Chromatogr B 781:181-206

Capitan P, Malmezat T, Breuillè D, Obled C (1999) J Chromatogr B 732:127-135

Circu ML, Aw TY (2008) Free Radic Res 42:689-706

Cohn VH, Lyle J (1966) Anal Biochem 14:434-440

Ellman GL (1959) Arch Biochem Biophys 82:70-77

Fanjul-Moles ML, Prieto-Sagredo J, Lopez DS, Bartolo-Orozco R, Cruz-Rosas H (2009) Photochem Photobiol 85:78-87

Filho DW (1996) Braz J Med Biol Res 29:1735-1742
Frassanitoa R, Rossi M, Dragani LK, Tallarico C, Longo A, Rotilio D (1998) J Chromatogr A 795:53-60

Green JM (1996) Anal Chem 68:305A-309A

Guan X, Hoffman B, Dwivedi C, Matthees DP (2003) J Pharm Biomed Anal 31:251-261

Hissin PJ, Hilf R (1976) Anal Biochem 74:214-226

Hjeltnes B, Samuelsen OB, Svardal AM (1992) Dis Aquat Org 14:3133

Hottenroth S, Völkel W, Fechner T, Bopp S, Römpp A, Klemm O, Frank H (2000) 1st International Symposium on Advances in Chromatographic and Electrophoretic Separations (ACES), Bayreuth

Humbert B, Nguyen P, Obled C, Bobin C, Vaslin A, Sweeten S, Darmaun D (2001) J Mass Spectrom 36:726-735

Humbert B, Nguyen P, Martin L, Dumon H, Vallette G, Maugère P, Darmaun D (2007) J Nutr Biochem 18:10-16

Iwasaki Y, Saito Y, Nakano Y, Mochizuki K, Sakata O, Ito R, Saito K, Nakazawa H (2009) J Chromatogr B 877:3309-3317

Ji LL, Leeuwenburgh C (1995) Glutathione and exercise. In: Somani S (ed) Pharmacology in exercise and sports. CRC, Boca Raton, pp 97-124

Kato H, Okamoto M, Yamashita K, Nakamura Y, Fukumori Y, Nakai K, Kaneko H (2003) J Toxicol Sci 28:19-24

Kovačević TB, Borković SS, Pavlović SZ, Despotović SG, Saičić ZS (2008) Arch Biol Sci Belgrade 60:59-66

Küster A, Tea I, Sweeten S, Rozé JC, Robins RJ, Darmaun D (2008) Anal Bioanal Chem 390:1403-1412

Li ZH, Zlabek V, Grabic R, Li P, Randak T (2010) Comp Biochem Physiol C 152:392-398

Lomaestro BM, Malone M (1995) Ann Pharmacother 29:1263-1273

Loughlin AM, Skiles GL, Alberts DW, Schaefer WH (2001) J Pharm Biomed Anal 26:131-142

Maciel FE, Rosa CE, Santos EA, Monserrat JM, Nery LEM (2004) Can J Zool 82:1871-1877

Miszczyk M (2007) Prog Plant Protect 47(4):75-78

Mitamura K, Sogabe M, Sakanashi H, Watanabe S, Sakai T, Yamaguchi Y, Wakamiya T, Ikegawa S (2007) J Chromatogr B 855:88-97

Monostori P, Wittmann G, Karg E, Túri S (2009) J Chromatogr B 877:3331-3346

Muriana FJ, Ruiz-Gutierri V, Bolufer J (1993) J Biochem 114:404407

Napierska D, Thebault MT, Pempkowiak J, Skorkowski EF (1997) Oceanologia 39:137-146

Pastore A, Federici G, Bertini E, Piemonte F (2003) Clin Chim Acta 333:19-39

Peña-Llopis S, Ferrando MD, Peña JB (2002) Chemosphere 47:485497

Piccoli G, Fiorani M, Biagiarelli B, Palma F, Potenza L, Amicucci A, Stocchi V (1994) J Chromatogr A 676:239-246

Power A, Sheehan D (1996) Comp Biochem Physiol C 114:99-103

Schilderman PA, Moonen EJ, Maas LM, Welle I, Kleinjans JC (1999) Ecotoxicol Environ Saf 44:241-252

Tanphaichitr V, Horne DW, Broquist HP (1971) J Biol Chem 246: 6364-6366

Trabesinger AH, Boesiger P (2001) Magn Reson Med 45:708-710

Trabesinger AH, Weber OM, Duc CO, Boesiger P (1999) Magn Reson Med 42:283-289

Yilmaz K, Keser S, Tuzcu M, Güvenc M, Çetintas B, Irtegün S, Tastan H, Sahin K (2009) J Anim Vet Adv 8:343-347 